\title{
GPR Applications across Engineering and Geosciences Disciplines in Italy: a Review
}

\author{
A. Benedetto, F. Tosti, L. Bianchini Ciampoli and F. D’Amico
}

\begin{abstract}
In this work, a review of the main groundpenetrating radar (GPR) applications, technologies, and methodologies used in Italy is given. The discussion has been organized in accordance with the field of application, and the use of this technology has been contextualized with cultural and territorial peculiarities, as well as with social, economic, and infrastructure requirements, which make the Italian territory a comprehensive large-scale study case to analyze. Firstly, an overview on the use of GPR worldwide compared to its usage in Italy over the history is provided. Subsequently, the state of the art about the main GPR activities in Italy is deepened, and divided according to the field of application. Notwithstanding a slight delay in delivering recognized literature studies with respect to other forefront countries, it has been shown how the Italian contribution is now aligned with the highest world standards of research and innovation in the field of GPR. Finally, possible research perspectives on the usage of GPR in Italy are briefly discussed.
\end{abstract}

Index Terms - ground-penetrating radar (GPR), applications, engineering, geosciences, Italy

\section{INTRODUCTION}

Many efforts from several scientific disciplines have been devoted over years to identify an effective technique capable of interpreting the hidden response of the ground reliably, and different methods of inspection have been developed accordingly. The answer to this issue has not been uniquely satisfied, since a fair number of techniques have demonstrated to be overall suited for this purpose. In this framework, ground-penetrating radar (GPR) is nowadays considered as one of the most powerful geophysical non-destructive tools which has gained considerable interest among scientists and engineers thanks to the wide range of expertise and applications that can be covered. GPR is intrinsically a technology oriented towards applications, whose structure and electronics is relatively variable according to the target characteristics. Basically, structures and changes in material

Paper submitted for review on October $26^{\text {th }} 2015$ thanks to the network activities carried out within the EU funded COST Action TU1208 "Civil Engineering Applications of Ground Penetrating Radar."

Andrea Benedetto, Department of Engineering, Roma Tre University, Via Vito Volterra 62, 00146 Rome, Italy, (andrea.benedetto@uniroma3.it)

Fabio Tosti, School of Computing and Engineering, University of West London (UWL), St Mary's Road, London W5 5RF. (Fabio.Tosti@uwl.ac.uk)

Luca Bianchini Ciampoli, Department of Engineering, Roma Tre University, Via Vito Volterra 62, 00146 Rome, Italy, (luca.bianchiniciampoli@uniroma3.it)

Fabrizio D'Amico, Department of Engineering, Roma Tre University, Via Vito Volterra 62,00146 Rome, Italy, (fabrizio.damico@uniroma3.it) properties can be detected by GPR through the use of electromagnetic (EM) fields, which penetrate lossy dielectric materials to some depth up to their absorption. It is based on the scattering and/or reflection by changes in impedance of EM waves [1]. The recognition of the signal is relatively easy, as the return signal is shaped very similar to the emitted signal. The depth, shape and electromagnetic properties of the scattering of the reflecting object affect the time delay, as well as the differences in phase, frequency and amplitude. Going through the history of GPR technology and its use worldwide, one of the first applications can be traced back to the first half of the twentieth century, and dealt with the use of radio wave propagation above and along the surface of the Earth [1]. The first documented application was later performed by El Said [2], who attempted to identify the water table depth in the Egyptian desert by knowing the distance between the receiver and the transmitter and measuring the time delay of the received signal. Over time, this technology witnessed great development within several different fields of application spanning from demining [3-7] to lunar explorations [8-11], and including glaciology [12], archaeology [13], geology [14, 15], and of course, civil engineering [16].

This work aims at reviewing the state of the art on the use of GPR in Italy, from the beginning up to the most recent applications. The Italian case is worth to be deepened as one comprehensive large-scale study case, wherein the complexity of territorial, naturalistic, historical, cultural, and socioeconomical features has effectively met the flexibility and high potential offered by the GPR technology. Firstly, the heterogeneity of its territory offers direct applications for GPR in a large range of fields, including geology, seismology, hydraulics and glaciology. Besides, the highest number of cultural UNESCO World Heritage sites [17] has generated a high sensitivity towards heritage monitoring and the use of maintenance technologies, which has progressively enhanced. In addition, with the Italian road network being one of the densest worldwide in relation to the territory available [18], economical investments are increasingly being addressed towards effective maintenance and rehabilitation policies by means of high-efficient survey technologies. These main features along with other specific Italian peculiarities that will be analyzed in this review, have acted both as an impulse for spreading this technology within the national market and overseas, and as a challenge for improving its performances through high-quality scientific contributions, making Italy one of the most active and fruitful countries in the field.

From a closely scientific perspective, the earliest Italian 


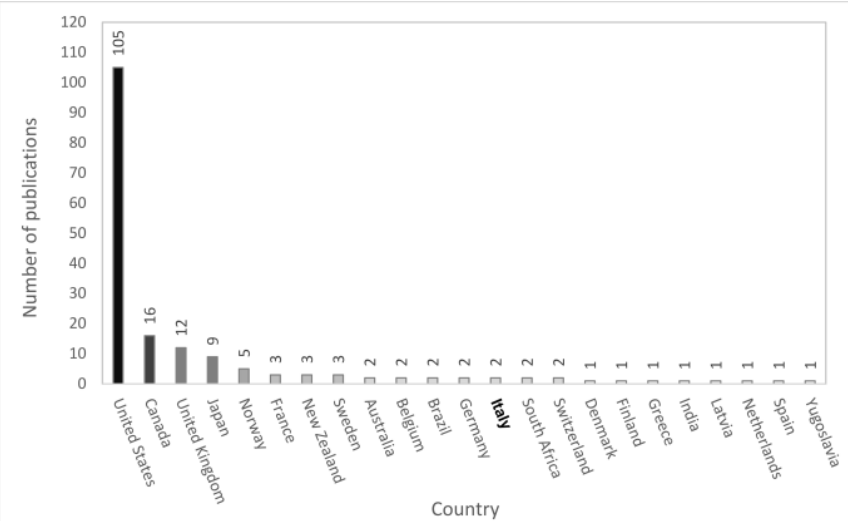

Fig. 1. Worldwide contribution on the production of GPR documents by country in the period 1976 - 1995 [19].

documented contribution falls slightly behind other countries like United States, Canada and United Kingdom (Figure 1), since the first works on GPR authored by Italian researchers were released in 1995, and dealt with, respectively, the analysis of signal propagation [20] and geological issues [21].

Besides, first Italian GPR applications for archaeological purposes date back to the same period [22, 23]. In the years following, the GPR-based research has started to embrace more fields of application from different disciplines: geological investigations [24], the use of numerical simulation of the GPR signal for retrieving material responses [25] and analyzing the GPR applicability in planetary explorations [26], together with the automatic detection of multilayered structures [27] demonstrate the growing interest of the Italian research community on GPR technologies and methodologies, since it is nowadays aligned to the highest research production standards worldwide. As shown by Figure 2, by 2015 Italy is within the first five countries publishing in the area of GPR.

A great contribution by the Italian research to the GPR world community came from the civil engineering area, wherein considerable efforts have been devoted to the use of GPR in transport infrastructures since the first years of the noughties [28, 29] and all over the last decade [30-32]. Lastly, it is worth mentioning the Italian contribution for the enhancement of the processing techniques of the GPR signal [33-35], as well as for the development of innovative and performing hardware configurations [36]. As for the latter, it is worth noting some important innovations, such as the development of a reconfigurable GPR system [37] capable to modify the EM parameters in real time for reaching higher performances [38, 39], and the introduction of systems equipped with antenna arrays capable to perform multi-offset measurements in real time $[23,40]$. The state of the art about GPR activities in Italy is discussed in Section 2 according to the field of application. The selection process of the papers analyzed in this Section has been made according to i) the number of citations collected in relation to the year of publication, as retrieved from the most recognized international scientific citation indexing services, and ii) scientific relevance criteria, intended as the contribution brought to the international scientific community in terms of development and novelties introduced. As for this latter point, it is worth to point out that it has to be interpreted as reflecting the scientific thought of the authors. Finally, Section 3 deals with conclusions and future perspectives on the applicability of GPR in Italy.

\section{GPR ACTIVITIES IN ITALY: STATE OF THE ART}

\section{A. Structures and Hydraulics}

\section{1) Structures}

The use of the GPR technology in structural engineering is nowadays established and wide-ranging. It is worth mentioning the location of reinforcing bars and metallic conduits, the assessment of concrete lining thicknesses, the investigation of highly-wet water spots in bearing structures, the detection of voids and cracks, the assessment of rebar sizes, and the 3D reconstruction of detailed structural elements [41]. When considering the GPR-related Italian contribution in this area, it must be mentioned the impact brought by the nature of the Italian territory. Indeed, statistics from seismic databases have identified Italy as the most seismically active country of the Mediterranean Area [42]. According to this, it is not surprising that one of the main focuses of the Italian research community in this field is represented by the seismic evaluation of structural elements, in terms of both prevention and damage diagnostics. Concerning seismic prevention, Barrile and Pucinotti [43] developed a thorough work mainly focused on the bi-dimensional and three-dimensional reconstruction of structural elements in a reinforced concrete structure. To this purpose, a ground-coupled pulsed GPR system with a $1600 \mathrm{MHz}$ center frequency antenna was employed on a number of beams and columns of reinforced concrete structure. Concerning the reconstruction of punctual structural elements, the work by De Domenico et al. [44], focused on the exact location of the foundation plints, is also worth to be mentioned.

In the study by Valle et al. [45], the authors have compared two different approaches to improve the resolution of the radar surveys, by using real and synthetic data on structural elements such as walls and pillars. Firstly, travel-time and amplitude tomography methods were applied, then migration and diffraction tomographies were adopted. According to the results achieved, the authors were capable to single out advantages and drawbacks of the proposed approaches.

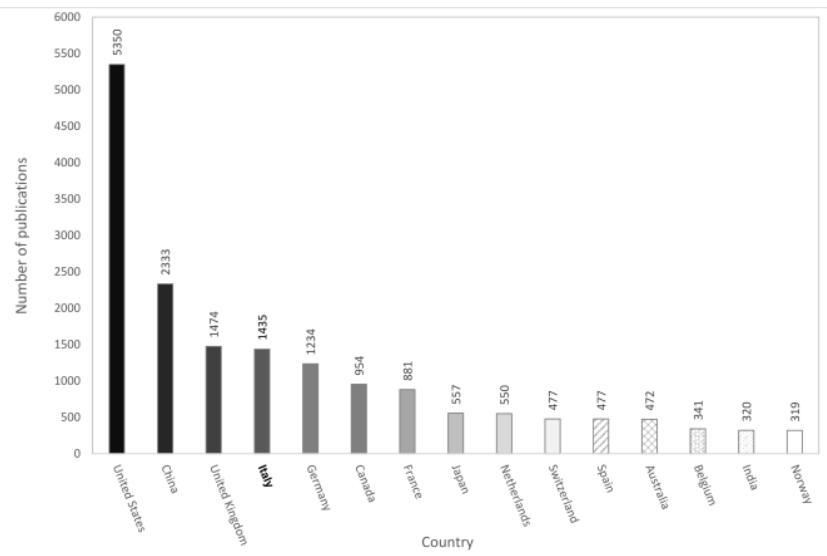

Fig. 2. Top 15 countries worldwide contributing to publish GPR-based documents in the period 1976 - 2015 [19]. 
With similar purposes, Soldovieri et al. [46] used a frequency domain inverse scattering approach, based on a linear model of the EM scattering. The goal of this study was to overcome the issue of the relationship between wavelength and dimension of the scatterer. The authors analytically assessed the capability of the linear inverse model in terms of scatterer imaging, by identifying the optimal frequency step and the diffraction tomography arguments. The research was supplemented by several reconstructed scenarios related to synthetic and experimental data for the simulation of real environmental conditions. With regard to the damage assessment, a similar approach specifically focused on cracks characterization was later experimented by Bavusi et al. [47] in the town of L'Aquila, Italy. By using tomographic techniques, the authors were capable to reconstruct different lines of reinforcing steel bars and defects inner to a number of structural elements damaged by the tragically-known seismic event recorded in the territory of L'Aquila, on April 2009.

A further crucial issue affecting a considerable number of buildings, structures, and infrastructures in Italy is of course related to their aging. It is explanatory reminding that a great part of the Italian highway network was realized within the Seventies [48], due to the economic growth dating back to the first years of sixties. This has reflected in a considerable amount of concrete artifacts that is nowadays turning around fifty years of service, thereby requiring important maintenance and rehabilitation activities. In addition, the economic prosperity of sixties generated a relevant raise of urbanization, which was in many cases out of any control or regulation, with the total amount of buildings, mainly made of concrete, passing from $10.7 \mathrm{mln}$ in 1951 to $19.7 \mathrm{mln}$ in 1991 . This fact has implied nowadays a general need for effective and efficient concrete inspections in Italy, to which several GPRbased research activities have been in turn oriented. To this purpose, Capizzi et al. [49] aimed at evaluating the capability of GPR in assessing the strength of concrete and reconstructing buried objects, in comparison with ultrasound (US) techniques. A polyvinyl chloride (PVC) pipe was positioned inside the concrete sample. By means of GPR tomography techniques, the authors were capable to reliably and efficiently reconstruct the cavity in the sample. The strength characterization of the concrete, mainly consisting in the correlation between permittivity and compression strength, was postponed to further investigation.

\section{2) Hydraulics}

With regard to the application of GPR in hydraulic engineering, remarkable international efforts have been addressed to a wide range of research-oriented works and study cases, spanning from basic research investigations, up to the management and protection of water resources in great works of civil engineering. Above all, we can cite the reconstruction of sewer lines, the location of underground storage tanks and the mapping of water tables, up to the evaluation of moisture in various soil types and construction materials at several scales of investigation using different GPR systems and signal processing techniques $[50,51]$.

Under a hydrological perspective, the Italian territory is known to be extremely peculiar. A first point of uniqueness consists in the high percentage of aquifer-withdrawn potable water, which amounts to $85.6 \%$ out of the total available [52]. This fact implies a serious issue related to both the quality control of water for the safety of the users' health, and the lowering of the ratio between the water leaked during conduction and the amount of water withdrawn. In this framework, several research activities focused on the application of GPR for characterizing aquifers and detecting leakages in water pipes have been developed. Beserzio et al. [53] have successfully attempted at reconstructing the geometry and architecture of the fluvial stratigraphy for the Quaternary Po Plain, Italy. With the purpose of improving the ongoing imaging methodologies, the authors have compared the results outcoming from several non-destructive testing (NDT) methods, namely, the vertical electrical sounding (VES), the electrical resistivity ground imaging (ERGI), and GPR. Strengths and limits of these techniques are discussed herein, and the potential of their integration for an accurate three-dimensional reconstruction of sedimentary units is also shown. On the contrary, Carcione [25] faced the topic of the characterization of aquifers using a simulation approach. The author proposed a theoretical model capable to reproduce the behavior of radio waves in realistic media, by simulating reflection, refraction and diffraction phenomena, in addition to the relaxation mechanism and the anisotropic properties of the medium investigated. Therefore, this method was successfully applied for preliminarily assessing the saturation of a porous media, as well as for evaluating the contamination of a sand aquifer. The infiltration process in the portion of subsurface located above an aquifer, i.e., the vadose zone, was instead analyzed by Cassiani et al. [54], by comparing data from both GPR and time domain reflectometry (TDR) measurements performed over a test site. Different central frequencies of investigation were employed herein. The results have confirmed the reliability of GPR in detecting the variation of moisture in a progressively saturated medium.

With regard to those applications focused on leak detection in underground pipes, it is worthwhile mentioning the study performed by Cataldo et al. [55], wherein the potential of different geophysical methods suited for purposes was evaluated. To this aim, TDR, GPR and electrical resistivity tomography (ERT) were applied in both laboratory and onfield environment to water pipes differently leaked. The GPR device was equipped with a double set of antennas, with center frequencies of $200 \mathrm{MHz}$ and $600 \mathrm{MHz}$. GPR and TDR were found to be reliable tools for detecting water leakage spots. Nevertheless, the authors have reported the misleading impact on the GPR signal of some potential buried objects.

A further peculiarity of the Italian territory consists in the close relationship between its hydrogeological complexity and the capillary character of the transport network, which makes the management of water-retaining structures a crucial issue to be tackled. Several studies have then investigated the potential of GPR in assessing the status of river embankments.

Di Prinzio et al. [56] analyzed the reliability of GPR in detecting the presence of voids and discontinuities in levees and river embankments, which effectively represent a comprehensive strategy to localize early-stage damages. To this purpose, surveys along several kilometers of two embankments situated nearby the Italian town of Bologna were carried out using a GPR unit with a low central 
frequency of investigation, i.e., $250 \mathrm{MHz}$. The authors were able to clearly identify void spots, consisting in general of animal burrows, despite the interference of several factors affecting the quality of the data collected, such as the dependence on earlier weather conditions or the presence of vegetation over the unmaintained embankments. Moreover, it was also highlighted how the use of a suitable and unique central frequency of investigation may represent a critical issue, especially when evaluating targets at different depths. Such topic was indeed tackled by Perri et al. [57] by comparing data collected on the embankments of the Tagliamento river, near Venice, Italy, by using a $600 \mathrm{MHz}$ central frequency GPR system, together with other geophysical tools. GPR has herein proved to be a relatively useful non-destructive technology, capable to support maintenance operations in hydraulic engineering great works.

As far as the evaluation of soil moisture is concerned, Strobbia and Cassani [58] have tackled the topic of moisture mapping in shallow and thin low-velocity soil layers. By implementing an inverse multilayer GPR waveguide model, it was endeavored to infer both the wave velocity within the medium and the layer thicknesses using a stochastic-based approach.

A similar statistical approach was employed in further studies, wherein low frequencies GPR systems were used to reconstruct water content profiles in soils by performing crossborehole zero offset profiles (ZOP) [59, 60].

\section{B. Transport Infrastructures}

This Section reviews the major uses of GPR in Italy in transport engineering by fields of application, namely, roads, railways, and airports. A further subsection will be devoted to critical transport infrastructures, such as bridges and tunnels, whose strategic importance deserves a separate discussion.

\section{1) Roads}

According to Saarenketo [61], GPR road applications can be broadly divided into four main categories, namely, i) surveys needed in designing new roads, ii) surveys carried out for the rehabilitation design of existing roads, iii) quality control or quality assurance surveys in road projects, and iv) surveys carried out for pavement management systems.

Worldwide, there is a remarkable number of works dealing with the application of GPR in roads and streets [61]. In Italy, it is worth noting that most of the freight and passenger transport takes place on the road. The results of national inquiries depict a broadly extended road network, with increasing traffic volumes [62,63]. Such peculiarities have favored the use of GPR especially in roads more than in other transport infrastructures (Figure 3), whereby a considerable number of applications can be found for both subgrade soils, unbound and bound pavement layers.

The Italian GPR-related research focused on the assessment of the physical properties of subgrade soils and load-bearing layers has been very fruitful since the early noughties, when Benedetto and Benedetto [28] presented a semi-empirical approach for the evaluation of the relative dielectric permittivity of subgrade soils, based on a Gauss function which takes into account the relative dielectric permittivity of both the dry and the saturated material, as well as its particle size properties. One multi-frequency GPR system with ground-coupled antennas, $600 \mathrm{MHz}$ and $1600 \mathrm{MHz}$ central frequency of investigation, was used for the laboratory tests on two soil types, which in turn were oven-dried and progressively wetted at several known water contents up to saturation. It was observed how a mono-granular soil has a tendency to change its relative dielectric permittivity more rapidly than a heterogeneous soil particle size, since a faster change from a viscous to a free water status may occur. This approach was later deepened by Benedetto [30], who compared the results, in terms of $\varepsilon_{r}$, achieved by testing four types of soils, with empirical and theoretical models.

Starting from 2005, considerable efforts have been devoted towards the GPR-based evaluation of water content in subgrade soils and unbound pavement layers. Fiori et al. [64] investigated the relationship between the relative dielectric permittivity of soils and their volumetric water content. The effective permittivity of the soil was here derived as a function of the water content by using the effective medium approximation (EMA) technique after modeling the porous medium as a Multi Indicator structure with spherical elements of variable radii $R$. The derived formula was tested against controlled laboratory experiments and it has shown that the approximated relationship behaves quite well in a broad range of water contents $\theta$, being the R-squared value $R^{2} \approx 0.98$.

More recently, Benedetto and Pensa [31] have carried out a GPR-based experimental survey for calibrating a number of geophysical parameters and validating the reliability of an indirect diagnostic method for the detection of pavement damages. Water was here injected within a flexible pavement structure over a period of several hours. The dielectric constant and the water content in the unbound aggregate layer were estimated by the GPR travel time data, as well as the variations of water content in time and the critical areas with low rates of water infiltration. Such approach has proved to be effective at diagnosing the presence of clay and the cohesive nature of certain soils that may compromise the bearing capacity of load-bearing layers and induce structural damage. A step beyond the common practices established in Italy and worldwide for moisture sensing with GPR in typical subgrade soils was done in 2010 by Benedetto [65], who processed the GPR signal in the frequency domain on the basis of the Rayleigh scattering principles, according to the Fresnel theory. The main assumption relies on the fact that in unsaturated soils the water droplets are capable to scatter EM waves [66],

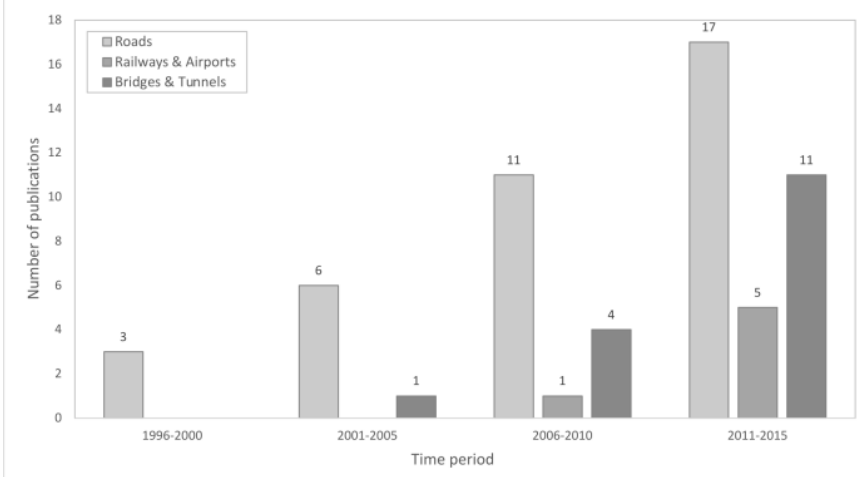

Fig. 3. Number of documents published in Italy by five-year periods from 1996 up to 2015 in the area of transport infrastructures [19]. 
thereby an extra-shifting of the central frequency of the wave spectra can be added to the one which is mainly related to the medium properties [67, 68]. In line with this, several relationships were provided between the shift of the peak and the water content for different types of soil under controlled laboratory conditions. The approach has been validated at the whole range of investigation scales [69-71], providing good results and promising applicability.

Much more recently, the Italian contribution on the GPR use for preventing structural damages in load-bearing layers has been focused on the possibility to detect and quantify clay content [72]. It is well-known that clay presence is closely related to moisture, due to its considerable swelling properties [73], thereby it is capable to exert significant effects on the stability of the soil behavior under loading. In this regard, Tosti et al. [74] have employed different GPR methods and techniques to non-destructively investigate the clay content in sub-asphalt soil samples compacted in laboratory environment. The experimental layout has provided the use of three types of soil with progressively increasing percentage of bentonite clay, and two different GPR instruments were used for the EM measurements at each step of clay content. In particular, a ground-coupled pulsed radar system, $500 \mathrm{MHz}$ central frequency, and a vector network analyzer (VNA) spanning the $1-3 \mathrm{GHz}$ frequency range were here employed. The signals collected were processed using the Rayleigh scattering method, the full-wave inversion technique [75], and the time-domain signal picking technique. Overall, promising results were achieved for the detection of clay.

The electrical behavior of clayey soil samples was also investigated at a smaller scale by Patriarca et al. [76] using two measurement techniques, namely, a coaxial transmission line and a monostatic stepped frequency GPR. The effect of growing water contents was analyzed for several sand-clay mixtures. The results from the two measurement techniques were compared for the end-member case of maximum clay, namely, $25 \%$ in weight, with water contents growing progressively up to saturation. It was confirmed the high impact of water over the electrical properties of materials, and it was also proved how the frequency dependence of the soils investigated is sensitive to the presence of clay, by showing distinctive features regardless of the soil mineralogy. Such esults were confirmed by a similar experience conducted by Tosti et al. [77] with different GPR systems.

Within the Italian contribution in the GPR-based research focused on the bound structure of a road pavement, an inverse scattering approach for pavement profiling was presented by Spagnolini and Rampa [78], who determined layer thickness and permittivity of the asphalt. Benedetto et al. [79] proposed a study for assessing the reliability of an optimal signal processing algorithm for pavement inspections. Basically, the analyses were carried out as a function of two thresholds, with the first one set for taking into account the error of detecting possible damages and checking their predictability, and the second one for determining the nature of the damage. An optimum detection procedure implementing the classical Neyman-Pearson radar test was performed. A reasonable performance has been achieved by exploiting the spatial correlation properties of the signal received, as a result of a proper analysis of the GPR images.
In Tosti et al. [80] an off-ground GPR system, $1 \mathrm{GHz}$ central frequency of investigation, was employed to investigate a large-scale rural road network. Homogeneous pavement sections were singled out according to a comprehensive checklist of elements of practical use for GPR end-users. Useful advices on the system setup and calibration procedures are also given by the authors. The GPR system showed a very high productivity and a good effectiveness in detecting several causes of pavement damages.

Tosti and Umiliaco [81] and Benedetto et al. [82] investigated the possibility of simulating different types of pavement damages. The authors performed finite-difference timedomain (FDTD) simulations of the GPR signal on three different types of flexible pavement using two central frequencies of investigation, i.e., $600 \mathrm{MHz}$ and $1600 \mathrm{MHz}$, commonly employed in road surveys. Regular- and irregularshaped faults within hot-mix asphalt (HMA) layers and at the base-subbase interface, as well as potholes on the surface were here simulated by the GprMax2D numerical simulator [83].

Much more recently, Tosti et al. [82] proposed a promising semi-empirical amplitude-based model for inferring the mechanical properties of road pavements and materials from their dielectric characteristics. For calibrating the model, the authors employed ground-truth data arising from the use of a light falling weight deflectometer (LFWD).

\section{2) Railways}

GPR applications in railway engineering have experienced a huge advancement especially since the nineties. Overall, they can be divided into three main categories, namely, i) ballast surveys, ii) geotechnical investigations, and iii) structural quality assurances of new non-ballasted rail track beds [61].

To the best of our knowledge, there are no significant GPRrelated contributions worldwide concerning railway applications until 1994, when Göbel et al. [84] carried out some experimental tests to measure the ballast thickness and locating mudholes and ballast pockets, as well as for defining the soil boundaries of the subgrade. In addition, Saarenketo [61] argued that GPR was tested in some Finnish railways in the mid-eighties, although the results were not very encouraging due to a difficult data collection process and several processing problems. GPR has then started to become a technology acknowledged among railway engineers from the mid-nineties $[85,86]$.

According to literature statistics, Italy holds a total of 16742 $\mathrm{km}$ of rail network, being $11931 \mathrm{~km}$ electrified and $4811 \mathrm{~km}$ not electrified [62]. National statistics [87] point out how the railway transport in Italy can be considered secondary to road transport, and to other European countries' railway network. This is one of the reasons why GPR applications in Italy in this field can count on a lower number of contributions, which in turn have started later than in the rest of Europe, especially if compared to North European countries.

The Italian contribution in this area can be traced back to 1999 when IDS Ingegneria dei Sistemi carried out some pilot tests along an Italian high-speed railway track [88]. According to the results achieved, the same company developed an array of multi-frequency antennas wherewith it was possible to single out several damaging occurrences. With similar purposes, Caorsi et al. [89] developed a railway ballast inspection 
system capable to extract relevant geophysical parameters in real-time. A neural network-based method was exploited herein for solving the EM inverse problem through a "learning-by-examples" approach.

More recently, research efforts have been devoted to the EM characterization of the ballast material, mostly to analyze its response in case of fouling, whose occurrence leads to a drastic loss of performance. In line with this, Fontul et al. [90] have verified the dielectric values of the railway ballast used in Portuguese railways under controlled laboratory conditions through a multi-frequency GPR test, with the main goal of improving the GPR interpretation of the health conditions of railways. Additionally, GPR measurements and some test pits were performed in-situ for validating the dielectric permittivity values of a clean ballast achieved preliminarily in laboratory environment.

\section{3) Airports}

The international scenario of literature publications on the use of GPR in airfield environment can count on a lower number of contributions than in other fields of application.

Several possible applications to this purpose can be broadly mentioned, namely, i) the locating of voids and moisture trails in concrete runways and taxiways, ii) the locating of posttensioning cables in concrete elements, such as garages or bridges inner to the airports, iii) the detection of voids and delamination of concrete roofs, iv) the reconstruction of cables, conduits and rebars geometry in concrete pavements, v) the location of buried utilities and their leaks, and vi) quality control and quality assurance surveys [91].

As of 2014, 45 International airports can be counted in Italy, which serve more than 150 million of passengers moving from, to, and within its territory by plane [92]. The maintenance of airfields, and especially of runways and taxiways, is an issue always more perceived by airport administrations, in terms of both social and economic impacts. Many of the main international airports are providing technologies capable to predict effectively and reliably the evolution of damages in runway and taxiway pavements. Despite of their potential, there is still not a rightful number of research activities in this field.

Benedetto and Tosti [93] have faced the topic of the GPRbased characterization of the strength and deformation properties of the unpaved natural soils, which constitute the so-called Runway Safety Areas (RSA). To this purpose, deflectometric and GPR tests were carried out in both laboratory and field environment, at the Roma Urbe Airport, Rome, Italy. The GPR device employed here was a groundcoupled $600 \mathrm{MHz}$ and $1600 \mathrm{MHz}$ pulsed system, while information about the strength parameters were gathered on the field by using a LFWD, and by performing California bearing ratio (CBR) tests in laboratory environment. The authors firstly related the dielectric permittivity values of the soil investigated with its bulk density. The Young's elasticity modulus was then predicted by implementing a semi-empirical model, based on theoretical arguments and validated using ground-truth data. Relatively good results were achieved, although the authors suggest the need for widening the range of surveyed materials and to investigate the soil behavior under different known moisture conditions.

\section{4) Bridges and tunnels}

The lowering of the risk related to structural stability issues of transport lifelines, such as bridges or tunnels, is an important task that needs to be undertaken in order to avoid possible failures, which may lead to a lack of functionality and compromise the whole transportation network. In this framework, GPR can cover an important role in monitoring and assessing these infrastructures, due to its minimum interference with traffic while measuring and testing. The potential of GPR in bridge engineering was evaluated in [29] and [32]. Aiming at developing a highly reliable algorithm for the 3D tracking of cracks within the HMA layers of a bridge deck, the authors employed a bridge-dedicated GPR system consisting in two arrays of ground-coupled antennas with a central frequency of $2 \mathrm{GHz}$, to survey several bridges in the district of Rieti, Italy. The signals collected were processed and amplified, and a 3D matrix of signal amplitude values was then realized. Therefore, an amplitude threshold was calibrated to localize the paths of the cracks, by comparing the evidence of cracks on the field with the radar reflections and by assuming higher amplitude values related to cracks.

Still concerning bridge applications, it is worth to mention the work developed by Pucinotti et al. [94] in 2009, over a studycase bridge, situated in the district of Reggio Calabria, Italy. To this intent, different technologies were used. In particular, laser scanner technology (LST) and GPR were combined to reconstruct the surface and inner morphology of the structure, respectively. GPR showed a good reliability and efficiency in determining the geometry of steel reinforcements, the lacks of homogeneity, and the major damages.

With respect to tunnel engineering, Cardarelli et al. [95] made use of GPR in an integrated approach, to assess the health state of a tunnel set aside for potable water which caved-in due to a landslide. GPR and seismic surveys were carried out by availing of a twin tunnel, around $15 \mathrm{~m}$ far from the target. Three antennas were employed in a bistatic configuration, with a central frequency spanning from $200 \mathrm{MHz}$ to $450 \mathrm{MHz}$. The lower frequencies were especially useful in retrieving the number and the location of discontinuities, thereby indicating collapsed zones. The integration between GPR, seismic, and tomographic analysis led to minimize uncertain data and to infer useful information about the tunnel structural stability.

In line with the purposes of the former work, Piccolo and Zanelli [96] reconstructed the state of the geo-structure surrounding the lining of a tunnel designed for potable water conduction in the North-East of Italy. The authors surveyed 7 $\mathrm{Km}$ of tunnel lining using a pulsed GPR system with $100 \mathrm{MHz}$ and $500 \mathrm{MHz}$ central frequency antennas. The higher frequency allowed monitoring the lining thickness all over the scan length, while the lower one allowed detecting deeper inhomogeneities, e.g. cavities and cracks, up to $20 \mathrm{~m}$ distance.

\section{Underground utilities}

In most cases, the complexity of a network of underground pipes can carry telecommunication or electric cables, natural gas, potable and wastewater, but it can also develop as an underground oil pipeline or a tunnel network [97]. Several studies from nineties have been carried out worldwide for detecting and identifying the underground utilities. 
In Italy, a general lack of regulations and technical protocols in this matter has determined a really chaotic and uncontrolled use of the underground for the location of utilities. Consequently, it is not uncommon that roadworks get slowed by the damaging of unexpected utility pipes. A first national regulatory impulse dates back to 1999 , when the Italian Ministry of Public Works promulgated a directive encouraging public administrations to adopt a urban plan for the management of underground utilities. To this aim, several big Italian municipalities such as Milan and Venice have already redacted their own urban plan.

This occurrence has generated an important impulse for the national research in the field of GPR for detecting and classifying underground utilities. In this framework, one of the first initiatives is represented by the European co-funded projects GIGA and ORFEUS [98, 99]. Among their main objectives, it was foreseen the design and manufacturing of an improved, user-friendly GPR capable to provide highlydetailed information for no-dig installation of gas pipelines by means of horizontal directional drillings (HDD).

The possibility of gathering and interpreting the data in realtime holds a crucial role in the optimization process of costs and time efforts. In this sense, different studies proposing new integrated approaches for the processing of 3D GPR data have been developed $[100,101]$. These approaches make use of typical seismic algorithms, and build pre-stack reflection gathered by depth-migration processes for different propagation velocities. Such an operation allows estimating with high reliability both the position of scatterers and the propagation velocity of the EM wave.

Under a different perspective, the non-invasive and efficient detection of underground utilities can also hold a crucial environmental role. Indeed, since the cost of energy and water resources kept raising, an early-stage location of leaks in underground pipes can avoid economic and environmental wastes. In such a framework, Crocco et al. [102] proposed a tomographic approach for detecting leaking pipes. The authors were capable to obtain detailed information about metallic leaking pipes, by employing a "distorted" wave scattering model and generating synthetic GPR data with a 2.5D FDTD forward modeling solver.

\section{Geology and environment}

Over the last decades, GPR has been used for a huge number of documented applications in the geological and environmental fields. Since a great part of the Italian territory is classified as seismically active, the geological hazard analysis [41] is one of the most important topics tackled in this field. In such a framework, the palaeoseismology [103] discipline can cover a crucial role, since it is capable to exploit signs of ancient earthquakes by stratigraphic analysis for evaluating the geological hazard of a certain territory.

The first recognized Italian research activity on geological issues using GPR was carried out in the nineties by Pettinelli et al. [21], with the aim of verifying the capability of 1D and 2D EM models in reconstructing structural and stratigraphic soil features. The study gathers and cross-matches information coming from road cuts, scarp faces, and GPR surveys collected over a simple limestone stratified sequence, located nearby the city of Rovereto, in the south-eastern Italian Alps. Both 1D and 2D models revealed to be in good agreement with the data collected, although the 1D model has showed more difficulties in predicting the point of diffraction, such as the fractures in limestone.

On the contrary, Orlando [104] focused his efforts on the detection of low quality rock areas, under the hypothesis that the volumes of rock showing fractures and cavities backscatter the energy transmitted by a GPR system. The author employed a GPR system equipped with a $200 \mathrm{MHz}$ central frequency antenna, on different geological contexts, located in the middle part of the Appennini mountain chain. The results showed a good effectiveness of GPR in reconstructing the quality of the geological layers, according to the central frequency employed. In the same research area, it is also worth mentioning the study by Longoni et al. [105].

Concerning palaeoseismology, Pauselli et al. [106] adopted GPR techniques coupled with trench works to reach a direct and detailed level of information about palaeoseismic structures, nearby the town of Norcia, Italy. To this purpose, a ground-coupled GPR system was equipped with two antennas, $100 \mathrm{MHz}$ and $300 \mathrm{MHz}$ central frequencies of investigation, and employed over two areas, located alongside the Norcia fault. GPR proved to be very effective as complementary tool with former trench works. The authors individuated a great applicability of GPR for a better planning of trenching sites and for enhancing the geological information collected in neighbor areas. Similar goals and methodologies were adopted with reliable outcomes in [107]. More insights about the GPR application in palaeoseismology can be found in [108].

Next to the abundance in geological activities, Italy has also a strong agricultural tradition that has left, as heritage, more than 1.6 million of agricultural establishments [109] widespread over the whole territory of the country. In such a framework, it is clear how agricultural water management and soil water conservation bear a crucial role, with GPR being a primary tool for water content sensing, due to the influence exerted by water on the dielectric properties of soils. Di Matteo et al. [110] have faced the topic of relating shallow soil water content and surface dielectric parameters by performing numerical simulations. The authors showed a high correlation especially between the dielectric constant and the average envelope amplitude of the first portion of the GPR signal.

In a country like Italy, wherein the agricultural tradition and the need of quality assurance for foods meets the difficulties of managing the industrial expansion and its related toxic refuses, a further very important issue is related on how to ensure a direct, rapid and non-invasive detection of pollution in soils. In this field, Chianese et al. [111] developed a GPRrelated study case. With the purpose of characterizing the territory in terms of levels of soil pollution, the authors made use of geophysical surveys performed in the industrial area of Val Basento, in the Region of Basilicata, in Southern Italy. In more details, different magnetic devices were employed to measure the magnetic susceptibility and the gradient of the magnetic field, while a GPR system equipped with $200 \mathrm{MHz}$ 
and $400 \mathrm{MHz}$ nominal frequency antennas was used to evaluate the subsurface electromagnetic behavior of those areas with higher magnetic susceptibility values. In general, the integrated use of magnetic and EM methods allowed to detect and characterize buried pollutant objects and highly attenuated zones, probably related to polluted soils.

\section{E. Archaeology}

GPR has earned a wide acknowledgment in the archaeological community over the past decades. From the seventies until now, burial tombs, historic buried chambers and graves, campsites and pit abodes have been detected through GPR methods [112]. Interpretation of collected GPR data have often been supported by simulation processes from two or three-dimensional models [113].

By statistics, Italy is identified as the country owning the highest amount of UNESCO "World Heritage" sites [114]. Nevertheless, between 2001 and 2011 the funds for culture allocated by the Ministry for Cultural Heritage and Activities have suffered a lowering of about the $20 \%$ of allocations. In such a frame, GPR can hold a key role for its well-known nondestructive and cost-effective features. Therefore, a lively research community focusing on developing or improving the ongoing methodologies for archaeological GPR surveys is not surprising a. Pipan et al. [40] performed a study wherein the tasks of locating buried targets in archaeological areas, and testing 2D and 3D multi-fold methods for the characterization of the shape and the dimension of unknown objects are faced. To this purpose, the authors have thoroughly surveyed an area situated in the archaeological park of Aquileia, in Northern Italy, by means of a wide offset range of common mid-point (CMP) analyses, A 3D multi-fold (MF) data acquisition was finally performed, yielding an increment of the signal to noise ratio parameter. Such methodology led to an indication of potential archaeological targets buried below the surface.

Similar goals were pursued in the work of Basile et al. [115] by employing GPR methods to characterize in detail the shallower high-attenuation layers of one urban area presumably interested by buried archaeological structures, located nearby the town of Lecce, in Southern Italy. While GPR did not yield reliably information about the positioning of historical walls made of the same calcarenite, due to the weak EM contrast, it showed good performance in detecting and reconstructing the shape and the size of a barrel-vault cavity, which was later on confirmed by excavations.

Negri and Leucci [116] applied GPR methods combined with ERT, to assess the possible presence of voids and cavities in the subsurface of the Temple of Apollo in Hierapolis, in the Lycus Valley, Western Turkey. Three-dimensional GPR imaging allowed to detect artifacts located beneath the Temple of Apollo, while two-dimensional ERT imaging enabled to verify an active fault as it was suggested by geological, geomorphological and palaeoseismic former studies. With regard to the same archaeological site of Hierapolis, in Turkey, a similar integrated geophysical approach was adopted by Nuzzo et al. [117].

However, to the best of authors' knowledge, the first example in the Italian literature of a multimethod geophysical approach applied to archaeological surveys, dates back to 1999, when Sambuelli et al. [118] carried out some integrated geophysical inspections on a Roman archaeological site, nearby the town of Biella, in Northern Italy.

Orlando and Soldovieri [119] proposed two different processing methods for providing reliable interpretation of bad quality datasets. Such methods were applied to the archaeological case of the relocation of a Stele in the Ethiopian archaeological park of Axum, and consisted in a classic processing scheme and a microwave tomographic approach. By comparing these two approaches, the authors were capable to increase the quality of the information coming from $100 \mathrm{MHz}$ and $200 \mathrm{MHz}$ GPR antennas.

The lack of GPR data interpretation can be overstepped, on the other hand, by making use of EM numerical simulation, as proposed in [25] and [113].

In general, one of the main issues affecting archaeological GPR surveys, is the need for high-resolution data. This can be a critical point when referring to the optimization of time and costs. Francese et al [120] proposed a possible solution to this problem by using a multichannel GPR system mounted on a cart and equipped with 14 antennas with a central frequency of $400 \mathrm{MHz}$. Such set up allowed the authors to survey in half a day a considerable wide area (around $75000 \mathrm{~m}^{2}$ ) located in Northern Italy, in the archaeological site of "Le pozze", wherein the remains of a roman village were known to be buried. The data were then processed, with particular regard to the data geo-referencing by GPS. In the end, the boundaries of the buried structures were detected, thereby allowing drawing a comprehensive map of the whole archaeological site.

\section{F. Glaciology}

From literature studies, it is known how dry snow and ice are the geological media providing the best wave propagation performances for GPR pulses with frequencies above approximately to $1 \mathrm{MHz}$. Indeed, such investigated media show a very low attenuation rate (low conductivity) for these pulses and the absence of relaxation processes $\left(\varepsilon_{r}{ }^{\prime \prime}=0\right)$. The penetration depth reaches nowadays the dimension of kilometers [91]. Besides, GPR is considered an effective tool for evaluating the glacier subsurface, due to the mostly horizontal and continuous configurations of their layers, which provide reflection patterns of easy interpretation [91].

With respect to the Italian territory, in 1993 almost 1400 glaciers were counted on the Alpine arch, for an overall interested area of about $608 \mathrm{~km}^{2}$ [121]. The Alpine glaciers are mostly classified as temperate glaciers, thereby involving a high seasonal variability in terms of snowmelt runoff, which in turn guarantees water provision in dry and warm seasons. Therefore, important research contributions in the field of glaciological applications of GPR can be found in literature. A good level of knowledge about the physical properties of glaciers, such as depth, density, and structural configuration, revealed to be helpful not only in public safety (e.g., avalanche prediction, see Section 2.7.2), but also in environmental applications (e.g., climate change monitoring), energy supply 
(e.g., hydropower production) and in agricultural issues (availability of water sources for irrigation).

As far as the density of the media is concerned, it is worth mentioning the study carried out by Godio [122], who has used different GPR systems with antenna central frequencies spanning from $500 \mathrm{MHz}$ to $1500 \mathrm{MHz}$ on three different Alpin sites. The author employed the data collected to test the main theoretical relationships between the dielectric properties and the density of the dry snow. The results show a good predictive capability of GPR in mapping the vertical profile of the density for the dry snow, while the author argues that further work has to be done for detecting the micro-structure of the snow. In addition, Previati et al. [123] faced the same issue with similar purposes using a different approach. Indeed, a combined use of GPR and TDR was tested in this case to evaluate some physical properties of the snowpack. In the survey site, namely "Cime Bianche", close to the Ventina glacier, Italy, a pulsed GPR system with a central frequency of $900 \mathrm{MHz}$ was employed together with a TDR, which was helpful in calibrating the radar measurements. The results showed an accurate assessment of the snow depth, while statistical and geostatistical analyses demonstrated the need for high-density data collection, which highlighted the low applicability of traditional methods. More recently, Forte et al. [124] have focused their efforts on a reflection amplitude analysis with the aim of recognizing the nature of the subsurface layers (snow, firm or ice) with GPR. The proposed method was developed on the basis of synthetic data, then tested on the field, over the Glacier of Mt. Canin (SouthEastern Alps), by employing a GPR system equipped with a $250 \mathrm{MHz}$ shielded antenna. The authors assessed reliably the dielectrics of the layers, which were related to their densities.

\section{G. Demining and public safety}

\section{1) Mines detection}

During the nineties, the theme of demining for humanitarian purposes has assumed a key importance in the international political scenario. The International Workshop of Technical Experts of Ordnance Recovery and Disposal in the Framework of International Demining Operation, held in Stockholm in 1994, and especially the Ottawa Treaty [125], signed by 133 countries, including Italy, during the Anti-Personnel Mine Ban Convention of 1997, have witnessed this assumption.

The disposition of the Ottawa Treaty furnished a concrete impulse to the research and the industrial activities for developing more effective technologies in landmine detection [41]. In such a framework, GPR has been found to be an effective tool in reducing the false alarm ratio (FAR) affecting the most seldom-employed devices, such as EM induction metal detectors (MDs). Therefore, the GPR technology can accomplish the crucial task of classifying the detected targets by interpreting their EM response, more than detecting them [91]. Italy plays an important role in such a scenario, also due to the presence of the Joint Common Research (JRC) in ISPRA, in the district of Varese, Northern Italy. Here, a test site for unexploded ordnance (UXO) detection was arranged for the validation of a handheld system developed in the context of the HOPE (Handheld Operational Demining System) project, promoted by the European Union in the late nineties. The HOPE system first brought a multi-task approach for demining, involving EM and Magnetic sensors [126].

On the basis of this contribution, several Italian works can be found in literature concerning the development of multi-sensor systems for detecting and characterizing landmines in humanitarian activities. Alli et al. [127] reported about the data processing approach for the GPR array involved in an integrated system called DEMAND, which has provided the use of one MD. The aim of the study was to reduce the FAR index of the MD device, by integrating the GPR data. To this purpose, a vehicle-mounted densely sampled ultra-wide band (UWB) array was developed, which allowed to reconstruct a 3D imaging of the subsurface and to focus the whole polarization matrix. The data processing scheme was worked out on the basis of the field tests performed in a test-site in Sarajevo, Bosnia-Herzegovina, on a selection of antipersonnel and anti-tank mines. The authors were capable to provide a high level of characterization of the mine-like targets. As a result, the GPR application yielded a 30\% reduction of the FAR related to the single use of MD.

Balsi et al. [128] adopted an inverse approach, based on the results of FDTD simulations, for returning a more accurate detection of UXOs and landmines. GPR tests were performed by using a bistatic ground-coupled system with a $1 \mathrm{GHz}$ central frequency antenna on a $1.3 \mathrm{~m} \times 3.5 \mathrm{~m} \times 0.5 \mathrm{~m}$ sandfilled box with several mine-like objects buried beneath its surface. Hence, the data collected were compared with those achieved by performing FDTD simulation through the GprMax software [129]. The results highlighted good agreement between real and synthetic data, thereby proving the reliability of GPR in detecting buried metallic and nonmetallic targets. On the contrary, the authors noticed the need for a multi-sensor analysis to achieve an effective method for classifying the object detected.

A more recent attempt to realize a hardware and software system capable of automatically detecting and recognizing unexploded ordnances, was conducted by Nuzzo et al. [130]. The authors presented the system architecture and the first results of laboratory and on-site tests relative to a densely sampled GPR array, within the research project TIRAMISU. The antenna array holds a multichannel configuration yielding an approximate width of survey of $1.3 \mathrm{~m}$ in a single pass, and a fast 3D reconstruction of the surveyed volume. A real-time processing algorithm was developed and a number of tests was performed on canonical targets, such as metal pipes. At the current state of the study, encouraging results have been achieved for the first device prototype, although the integration of GPR and MD still needs to be improved.

\section{2) Forensics and public safety}

Police agencies or rescue operators frequently need to carry out surveys for locating bodies hidden or buried underneath surfaces in a quick and non-invasive manner. Common applications of GPR in this field are the location of graves, the recognition of human remains and the marks of former excavations [131]. GPR can be also used for locating movements beyond the walls and detecting natural or artificial tunnels in the subsurface, for security and rescuing purposes. 
It is also well known that the Italian territory is characterized by widespread mountainous areas, whose hydrogeological history can be classified as particularly unstable. To have an idea of the dimension of this issue, it is worth mentioning that around the $70 \%$ of Italian municipalities is affected by landslide activities. This fact assumes a relevant importance if we consider that after the Second World War the Italian territory was interested by a wide urban and infrastructural expansion, even in unstable areas [132]. Under a public safety perspective, this fact implies two main issues. Firstly, in case of landslide there may be a need for detecting people buried under debris in a very rapid time, with the highest possible accuracy. Secondly, since the Italian territory is characterized by several skiing resorts among the most frequented in Europe, the risk of persons buried by avalanches appears extremely serious. This pushes the authorities to seek always more rapid and effective technologies capable to locate bodies in time. In this framework, it is of evidence how GPR allows to detect more effectively nonmetallic objects with respect to other NDTs that typically are sensitive to the magnetic field.

A review about GPR applications on the detection of buried or trapped victims under snow or debris can be found in Crocco and Ferrara [133]. Another worthwhile Italian contribution in the forensic field is the multi-array tomographic approach proposed by Soldovieri et al. [134] for through-wall imaging (TWI) using GPR. TWI exploits EM waves at microwave frequencies for detecting hidden bodies. Such an application can be useful in both rescue and law enforcement or anti-terrorism operations. The authors presented an approach for a multi-array configuration consisting in a combination of data collected by each single array. Both direct and inverse processes were run on synthetic data representing known targets hidden by a fixed geometry room. The approach showed good reliability in detecting and localizing hidden objects and their complex geometry.

\section{CONCLUSIONS AND FUTURE PERSPECTIVES}

In this work, the main GPR technologies and methodologies employed in Italy have been reviewed. The GPR use in this country has been contextualized to its worldwide main usage across engineering and geosciences disciplines, discussing about the profiles of innovation brought by the Italian contribution, and the growth path registered throughout the years, which has seen a tremendous progress in the literature production with respect to the slight delay accumulated during the eighties and the early nineties from other forefront countries. Italy is now aligned with the highest international research standards in the field of GPR and ranks within the first four countries in publishing international research papers.

The discussion has been divided in line with the field of application, by contextualizing the use of GPR according to cultural and territorial peculiarities, as well as to specific social, economic, and infrastructure requirements. Overall, the first works on GPR authored by Italian researchers can be traced back in 1995, several years later than the first release in this area by the international community. From that time onwards, the development of the research in this field has experienced a significant increase, especially in some application areas. One of the main Italian contributions can be related to the transport infrastructure area, wherein the considerable rate of national freight transport as well as the articulated structure of the Italian territory have attracted remarkable research efforts. Within this field, road applications collect the major number of contributions, followed by railways, bridges, and tunnels. The location of underground utilities has seen also interesting insights brought by Italian researchers. To a lower but still significant way, geological and archaeological GPR-based applications have found a remarkable development starting from the first half of the nineties. The use of GPR in geology has been mostly related to palaeoseismic investigations, due to the frequent occurrence of seismic events within the Italian territory and to the need for providing effective prevention strategies. The applications of GPR in archaeology have been basically based on the use of low-frequency GPR antenna systems together with other NDTs, such as ERT and magnetometric surveys. Glaciological applications have also recorded a number of research works wherein several central frequencies of investigation have been used. Research efforts on using GPR in demining, forensics, and public safety and innovative algorithms and methodologies brought by Italian researchers have been also discussed. On the basis of the excellent trend of literature production recorded and according to the most recent and fruitful research activities carried out, future perspectives will reasonably see the contribution brought by Italy to the worldwide scientific community to further increase in the years coming. The transportation area, together with the geology and archaeology disciplines will be probably the engines of the growth of the Italian research and innovation profile in the near future. The integration with other highperformance NDTs will be the primary element of development on which to focus future activities for improving the reliability of the results. In addition, in line with many activities carried out in the past, the Italian contribution is expected to maintain a key role in the advancement of the GPR technology by implementing even more performant and application-dedicated devices and by developing increasingly effective algorithms and processing methodologies.

\section{REFERENCES}

[1] A. P. Annan, GPR-History, Trends, and Future Developments, Subsurface Sensing Technologies and Applications, Vol. 3, No. 4, 2002, 253-270 A. P. Annan, "GPR-History, Trends, and Future Developments," Subs. Sens. Tec. App., vol. 3, no. 4, pp. 253-270, 2002.

[2] M. El Said, "Geophysical prospection of underground water in the desert by means of electromagnetic interference fringes," in Proc. I.R.E., 1956.

[3] A. H. Waite, S.J. Schmidt, "Gross errors in height indication from pulsed radar altimeters operating over thick ice or snow, IRE International Convention Record, Part 5, pp. 38-54, 1961.

[4] J. C. Cook, "Radar exploration through rock in advance of mining," T. S. Min. Eng., vol. 254, pp. 140-146, 1973.

[5] W. T. Holser, R. J. Brown, F. A. Roberts, O. A. Fredrikkson, R. R. Unterberger, "Radar logging of a salt dome," Geophys., 1972.

[6] R. R. Unterberger, Radar propagation in rock salt, Geoph.. Prosp., 1978.

[7] R. Thierbach, "Electromagnetic reflections in salt deposits," J. Appl. Geophys., vol. 40, pp. 633-637, 1973.

[8] A. P. Annan, "Radio interferometry depth sounding: Part I-Theoretical discussion," Geophys., vol. 38, pp. 557-580, 1973. 
[9] G. Simmons, D. Strangway, A. P. Annan, R. Baker, L. Bannister, R. Brown, et al., "Surface Electrical Properties Experiment," Apollo 17: Preliminary Science Report, Scientific and Technical Office, NASA, Washington D.C., 15-1-15-14, 1973.

[10] S. H. Ward, R. J. Phillips, G. F. Adams, W. E. Brown Jr., R.E. Eggleton, P. Jackson, R. Jordan, W.I. Linlor, W.J. Peeples, L.J. Porcello, J. Ryu, G. Schaber, W.R. Sill, S.H. Thompson, J.S. Zelenka, "Apollo lunar sounder experiment," Apollo 17 Preliminary Science Report, Scientific and Technical Office, NASA, Washington, D.C., 22-1-22-26, 1973.

[11] F. Tosti, L. Pajewski, "Applications of radar systems in Planetary Sciences: an overview," Chapt. 15 - In: A. Benedetto \& L. Pajewski (Eds.), Civil Engineering Applications of GPR, Springer Trans. in Civil and Environmental Engineering Book Series, pp. 361-371, 2015.

[12] A. P. Annan, J. L. Davis, "Impulse radar soundings in permafrost," Radio Sci., vol. 11, pp. 383-394, 1976.

[13] L. T. Dolphin, et al., "Radar Probing of Victorio Peak, New Mexico," Geophys., vol. 43, no. 7, pp. 1441-1448, 1978.

[14] G. R. Olhoeft, "The electrical properties of permafrost," Ph.D. Thesis, University of Toronto, 172 pages, 1975.

[15] G. R. Olhoeft, "Electrical properties from $10^{-3}$ to $10^{+9} \mathrm{~Hz}$-physics and chemistry," in Proc. 2nd Int. Symp. Phys. Chem. of Porous Media, 1987.

[16] A. Benedetto, F. Benedetto, "Application Field-Specific Synthesizing of Sensing Technology: Civil Engineering Application of GroundPenetrating Radar Sensing Technology," Comp. Mat. Proc., 2014.

[17] ENIT (Ente Nazionale per il Turismo) - www.enit.it

[18] OECD, "Road traffic, vehicles and networks," Environ. Glance: OECD Indicators, OECD Publishing, 2013.

[19] Scopus.com < http://www.scopus.com/> (retrieved 30 December 2015).

[20] M. Bernabini, E. Pettinelli, N. Pierdicca, S. Piro, L. Versino, "Field experiments for characterization of GPR antenna and pulse propagation," J. Appl. Geophys., vol. 33 (1-3), pp. 63-76, 1995.

[21] E. Pettinelli, S. E. Beaubien, F. S. Marzano, N. Pierdicca, "Comparison of GPR field results from a stratified limestone terrain with model simulations," In Proc. Int. Geosci. Rem. Sens. Sympos, 1995.

[22] S. Malagodi; L. Orlando, S. Piro, F. Rosso, "Location of archaeological structures using GPR method. Three-Dimensional data acquisition and radar signal processing," Archaeol. Prosp., vol. 3, pp 13-23, 1996.

[23] M. Pipan, I. Finetti, F. Ferigo, "Multi-fold GPR techniques with applications to high-resolution studies: two case histories," Eur. J. Env. Eng. Geophys., vol. 1, pp. 83-103, 1996.

[24] E. Pettinelli, S. Beaubien, P. Tommasi, "GPR investigations to evaluate the geometry of rock slides and buckling in a limestone formation in Northern Italy,” Eur. J. Env. Eng. Geophys., vol. 1, no. 3, 1996.

[25] J. M. Carcione, "Ground-penetrating radar: wave theory and numerical simulation in lossy anisotropic media," Geophys., vol. 61, 1996.

[26] G. G. Ori, F. Ogliani, "Potentiality of the ground-penetrating radar for the analysis of the stratigraphy and sedimentology of Mars," Planet. Space Sci., vol. 44 (11 SPEC. ISS.), pp. 1303-1315, 1996.

[27] V. Rampa, U. Spagnolini, "Multi-layer detection/tracking for monostatic ground penetrating radar," In Proc. Int. Geosci. Rem. Sens. Sympos. (IGARSS), vol. 4, pp. 2038-2040, 1996.

[28] Benedetto, A., Benedetto, F. "Optimal algorithm for the ground penetrating radar signals processing in road pavement analysis and monitoring," In Proc. Int. Conf. Applic. Adv. Technol. Transp. Eng., pp. 370-377, 2002

[29] A. Benedetto, G. Manacorda, A. Simi, F. Tosti, "Novel perspectives in bridge inspections using GPR," Nondestruct. Test. Eva., vol. 27, no. 3, pp. 239-251, 2012.

[30] A. Benedetto, "Theoretical approach to electromagnetic monitoring of road pavement-applied geophysics and stochastic model," in Proc. 10th Int. Conf. Ground Penetrat. Radar, Delft, Netherl., 2004, 2, pp. 623-626.

[31] A. Benedetto, S. Pensa, "Indirect diagnosis of pavement structural damages using surface GPR reflection techniques," 2006.

[32] A. Benedetto, "A three dimensional approach for tracking cracks in bridges using GPR,” J. Appl. Geophys., vol. 97, pp. 37-44, 2013.

[33] M. Pipan, E. Forte, G. Dal Moro, M. Sugan, I. Finetti, "Multifold ground-penetrating radar and resistivity to study the stratigraphy of shallow unconsolidated sediments," Lead. Edge, vol. 22, 876-881, 2003.

[34] R. Persico, F. Soldovieri, "Effects of the background removal in linear inverse scattering," IEEE Trans. on Geos. Rem. Sens., vol. 46, no. 4, pp. 1104-1114, 2008.

[35] R. Rege, A. Godio, "Multimodal inversion of guided waves in georadar data," J. Appl. Geophys., vol. 81, pp. 68-75, 2012.

[36] L. Pajewski, F. Tosti, W. Kusayanagi. Antennas for GPR Systems. Chapter 2 - In: A. Benedetto \& L. Pajewski (Eds.), Civil Engineering
Applications of Ground Penetrating Radar, Springer Transactions in Civil and Environmental Engineering Book Series, 41-67, 2015.

[37] R. Persico, G. Prisco, "A reconfigurative approach for SF-GPR prospecting," IEEE Trans. Ant. Prop., vol. 56, no. 8, 2008.

[38] R. Persico, N. Romano, F. Soldovieri, "Design of a balun for a bow tie antenna in reconfigurable ground penetrating radar systems," Pr. Electromagn. Res. C, vol. 18, pp. 123-135, 2008.

[39] F. Soldovieri, E. Utsi, R. Persico, A.M. Alani, "Imaging of scarce archaeological remains using microwave tomographic depictions of ground penetrating radar data," Int. J. Ant. Prop., 2012.

[40] M. Pipan, L. Baradello, E. Forte, A. Prizzon, I. Finetti, "2-D and 3-D processing and interpretation of multi-fold ground penetrating radar data: a case history from an archaeological site," J. Appl. Geophys., vol. 41, no. (2-3), pp.271-292, 1999.

[41] D. J. Daniels, Ground Penetrating Radar, 2nd Edition. London, U.K.: The Inst. Electrical Eng, 2004.

[42] A. Rovida, R. Camassi, P. Gasperini, M. Stucchi (eds.), "CPTI11, the 2011 version of the Parametric Catalogue of Italian Earthquakes," Istituto Nazionale di Geofisica e Vulcanologia, Milano, Bologna, 2011.

[43] V. Barrile, R. Pucinotti, "Application of radar technology to reinforced concrete structures: a case study," NDT\&E. Int., vol. 38, no. 7, 2005.

[44] D. De Domenico, A. Teramo, D. Campo, "GPR surveys for the characterization of foundation plinths within a seismic vulnerability analysis," J. Geophys. Eng., vol. 10, no. 3, 2013.

[45] S. Valle, L. Zanzi, F. Rocca, "Radar tomography for NDT: comparison of techniques," J. Appl. Geophys., vol. 41, pp. 259-269, 1999.

[46] F. Soldovieri, J. Hugenschmidt, R. Persico, "Microwave tomography for GPR diagnostics of reinforced concrete," in Proc. 39th Europ. Micr. Conf. (EuMC), 2009.

[47] M. Bavusi, A. Loperte, V. La Penna, F. Soldovieri, "Rebars and defects detection by a GPR survey at a L'Aquila school damaged by the earthquake of April 2009," in Proc. 13th Int. Conf. Ground Penetrat. Radar (GPR 2010), Lecce, Italy, 2010.

[48] Anas S.p.A.: www.stradeanas.it

[49] P. Capizzi, P. Cosentino, S. Schiavone, "Can be GPR technique useful for strength characterization of concrete?," in Proc. 13th Int. Conf. Ground Penetrat. Radar (GPR 2010), Lecce, Italy, 2010.

[50] J. Huisman, S. Hubbard, J. Redman, A. P. Annan, "Measuring soil water content with ground penetrating radar: a review," Vadose Zone J., 2003.

[51] F. Tosti, E. C. Slob, "Determination, by using GPR, of the volumetric water content in structures, substructures, foundations and soil," in A. Benedetto \& L. Pajewski (Eds.), Civil Engineering Applications of GPR, Springer Trans. Civil and Environm. Eng. Book Ser, pp. 163-194, 2015.

[52] ISTAT, Giornata Mondiale dell'Acqua. Le statistiche dell'Istat, 2012.

[53] R. Beserzio, M. Giudici, M. Mele, "Combining sedimentological and geophysical data for high-resolution 3-D mapping of fluvial architectural elements in the Quaternary Po plain (Italy)," Sediment. Geol., vol. 202, no. (1-2), pp. 230-248, 2007.

[54] G. Cassiani, S. Ferraris, M. Giustiniani, R. Deiana C. Strobbia, "Timelapse surface-to-surface GPR measurements to monitor a controlled infiltration experiment," B. Geof. Teor. Appl., vol. 50, no. 2, 2009.

[55] A. Cataldo, R. Persico, G. Leucci, E. De Benedetto, G. Cannazza, L. Matera, L. De Giorgi, "Time domain reflectometry, ground penetrating radar and electrical resistivity tomography: a comparative analysis of alternative approaches for leak detection in underground pipes," NDT\&E. Int., vol. 62, pp. 14-28, 2014.

[56] M. Di Prinzio, M. Bittelli, A. Castellarin, P. R. Pisa, "Application of GPR to the monitoring of river embankments," J. Appl. Geophys, 2010.

[57] M. T. Perri, J. Boaga, S. Bersan, G. Cassiani, S. Cola, R. Deiana, P. Simonini, S. Patti, "River embankment characterization: the joint use of geophysical and geotechnical techniques," J. Appl. Geophys., 2014.

[58] C. Strobbia , G. Cassiani, "Multi-layer GPR guided waves in shallow soil layers for the estimation of soil water content," Geophys., 2007.

[59] M. Rossi, G. Cassiani, A. M. Binley, "A stochastic analysis of crosshole GPR zero-offset profiles for subsurface characterization," Vadose Zone J., vol. 11, no. 4, pp CP9, 2012.

[60] G. Cassiani, A. M. Binley, "Modeling unsaturated flow in a layered formation under quasi-steady state conditions using geophysical data constraints," Adv. Water Resour., vol. 28, pp. 467-477, 2005.

[61] T. Saarenketo, "NDT Transportation," Chapter 13 in text book "Ground Penetrating Radar: Theory and Applications" Ed- Jol., 2009.

[62] Ministero delle Infrastrutture e dei Trasporti, "Conto Nazionale delle Infrastrutture e dei Trasporti - Anni 2012-2013," Istituto Poligrafico e Zecca dello Stato S.p.A., 2014.

[63] ISTAT:http://noi-italia.istat.it/index.php?id=7\&L=0\&user_100ind_pi1 
\%5Bid_pagina $\% 5 \mathrm{D}=84 \& \mathrm{cHash}=$ bbaaea722dc7326dd2a8949cafa13345

[64] A. Fiori, A. Benedetto, M. Romanelli, "Application of the effective medium approximation for determining water contents through GPR in coarse-grained soil materials," Geophys. Res. Let., vol. 32, no. 9, 2005.

[65] A. Benedetto, "Water content evaluation in unsaturated soil using GPR signal analysis in the frequency domain," J. Appl. Geophys, 2010.

[66] P. Drude, The theory of Optics. Longmans, New York; 1902.

[67] G. Bekefi, A. H. Barrett, "Waves in dielectrics," In Electromagnetic Vibrations, Waves, and Radia-tion. MIT Press, Cambridge, MA, 1987.

[68] C.F. Bohren, D. Huffman, Absorption and scattering of light by small particles. New York: John Wiley; 1983.

[69] A. Benedetto, F. Benedetto, F. Tosti, "GPR applications for geotechnical stability of transportation infrastructures," Nondestruct. Test. Eva., 2012.

[70] A. Benedetto, F. Tosti, B. Ortuani, M. Giudici, M. Mele, "Soil moisture mapping using GPR for pavement applications," in Proc. IWAGPR 2013, Nantes, France, 2013.

[71] A. Benedetto, F. Tosti, B. Ortuani, M. Giudici, M. Mele, "Mapping the spatial variation of soil moisture at the large scale using GPR for pavement applications," Near Surf. Geophys. 2015.

[72] F. Benedetto, F. Tosti, "GPR spectral analysis for clay content evaluation by the frequency shift method," J. Appl. Geophys., 2013.

[73] M. N. Wuddivira, D. A. Robinson, I. Lebron, L. Bréchet, M. Atwell, S. De Caires, M. Oatham, S.B. Jones, H. Abdu, A.K. Verma, M. Tuller, "Estimation of soil clay content from hygroscopic water content measurements," Soil Sci. Soc. Amer. J., vol. 76, no. 5,, 2012.

[74] F. Tosti, C. Patriarca, E. Slob, A. Benedetto, S. Lambot, "Clay content evaluation in soils through GPR signal processing," J. Appl. Geophys., vol. 97, pp. 69-80, 2013.

[75] S. Lambot, E. C. Slob, I. van den Bosch, B. Stockbroeckx, M. Vanclooster, "Modeling of ground-penetrating radar for accurate characterization of subsurface electric properties," IEEE Trans. on Geos. Rem. Sens., vol. 42, pp. 2555-2568., 2004.

[76] C. Patriarca, F. Tosti, C. Velds, A. Benedetto, S. Lambot, E. C. Slob, "Frequency dependent electric properties of homogeneous multi-phase lossy media in the ground-penetrating radar frequency range," J. Appl. Geophys., vol. 1, no. 97, pp. 81-88, 2013.

[77] F. Tosti, A. Benedetto, L. Bianchini Ciampoli, S. Lambot, C. Patriarca, E. C. Slob, E.C. "GPR analysis of clayey soil behaviour in unsaturated conditions for pavement engineering and geoscience applications," Near Surf. Geophys., vol. 14, no. 2, pp. 127-144, 2016.

[78] U. Spagnolini, V. Rampa, "Multitarget detection/tracking for monostatic ground penetrating radar: application to pavement profiling," IEEE T. Geosci. Remote, vol. 37, no.1-2, pp. 383-394, 1999.

[79] A. Benedetto, F. Benedetto, M. R. De Blasiis, G. Giunta, "Reliability of signal processing technique for pavement damages detection and classification using ground penetrating radar,” IEEE Sens. J., 2005.

[80] F. Tosti, A. Benedetto, A. Calvi, "Efficient air-launched groundpenetrating radar inspections in a large-scale road network," in Proc. 3rd Int. Conf. Transp. Infrast. (ICTI 2014), pp. 703-709, 2014.

[81] F. Tosti, A. Umiliaco, "FDTD Simulation of the GPR signal for preventing the risk of accidents due to pavement damages," Int. J. Interd. Telecomm. Netw. (IJITN), vol. 6, no. 1, pp. 1-9, 2014.

[82] A. Benedetto, F. Tosti, L. Pajewski, F. D'Amico, W. Kusayanagi, "FDTD simulation of the GPR signal for effective inspection of pavement damages," in Proc. 15th Int. Conf. Ground Penetrating Radar (GPR 2014), Brussels, Belgium, 2014.

[83] F. Tosti, S. Adabi, L. Pajewski, G. Schettini, A. Benedetto, "Large-scale analysis of dielectric and mechanical properties of pavement using GPR and LFWD," in Proc. 15th Int. Conf. Ground Penetrating Radar (GPR 2014), Brussels, Belgium, art. pp. 868-873, 2014.

[84] C. Göbel, R. Hellmann, H. Petzold, "Georadar-model and in-situ investigations for inspection of railway tracks," in Proc. 5th Inte. Conf. Ground Penetrat. Radar, 1994.

[85] J. Hugenschmidt, "Railway track inspection using GPR - Some examples from Switzerland," in Proc.7th Int. Conf. Ground Penetrat. Radar, Lawrence, KS, USA, vol. 1, pp. 197-202, 1998.

[86] G. R. Olhoeft, E. T. Selig, "Ground penetrating radar evaluation of railway track substructure conditions," in Proc. 9th Int. Conf. Ground Penetrat. Radar, Santa Barbara, vol. 4758, pp. 48-53, 2002.

[87] ISTAT:http://noiitalia.istat.it/index.php?id=7\&L=0\&user_100ind_pi1\% 5Bid_pagina\%5D=84\&cHash=bbaaea722dc7326dd2a8949cafa13345

[88] G. Manacorda, D. Morandi, A. Sarri, G. Staccone, "A customized GPR system for railroad tracks verification," in Proc. of SPIE, 2002.

[89] S. Caorsi, G. Cevini, F. Burro, M. Sciotti, S. Sorge, "An innovative onboard processor for the real-time GPR monitoring of railway substructure conditions," in Proc. of the 4th Int. Workshop Adv. Ground Penetrat. Radar (IWAGPR 2007), art. no. 4278891, pp. 284-288, 2007.

[90] S. Fontul, E. Fortunato, F. De Chiara, "Evaluation of ballast fouling using GPR," in Proc. 14th Int. Conf. Ground Penetrat. Radar, 2014.

[91] H. Jol, Ground Penetrating Radar Theory and Application, 2008.

[92] Ente Nazionale per l'Aviaz Civile (ENAC), Dati di Traffico 2014, 2015.

[93] A. Benedetto, F. Tosti, "Inferring bearing ratio of unbound materials from dielectric properties using GPR: the case of Runaway Safety Areas," in Proc. Airf. Highw. Pavem.,2013.

[94] R. Pucinotti, M. Tripodo, "The Fiumarella bridge: Concrete characterisation and deterioration assessment by nondestructive testing," Int. J. Microstr. Mat. Prop., vol. 4, no. 1, pp. 128-139, 2009.

[95] E. Cardarelli, C. Marrone, L. Orlando, "Evaluation of tunnel stability using integrated geophysical methods," J. Appl. Geophys., 2002.

[96] M. Piccolo, A. Zanelli, "GPR surveys inside an hydroelectric watersupply tunnel to investigate the rock-concrete interface and the fractures affecting the host rocks," in Proc. 5th Int. Conf. GPR, 2002.

[97] N. A. Ismail, R. Saad, N. M. Muztaza, N. Ali, "Predictive mapping of underground utilities using ground penetrating radar," Caspian J. Appl. Sci. Res., vol. 2, pp. 104-108, 2013

[98] G. Manacorda, P. D. Loach, D. Pinchbeck, J.-P. Capdevielle, P.-F. Fournier, H. Scott, J.J. Kazik, M. Remeil, "The European GIGA project," in Proc. 10th Int. Conf. Ground Penetrat. Radar, 2004.

[99] G. Manacorda, M. Miniati, A. Simi, R. Guidi, S. Lelli, D. Vacca, D. Dei, D. Mecatti, H.F. Scott, M. Morey, M. Hamers, T. Schauerte, "A borehead GPR for horizontal directional drilling (HDD) equipment," in Proc. 15th Int. Conf. Ground Penetrat. Radar (GPR 2014), 2014.

[100]D. Molteni, P. Mazzucchelli, E. Cottino, N. Di Buono, "Real-time automated detection of buried utilities for 3D GPR investigations," in Proc. Near Surf. 2011 - 17th EMEEG, 2011.

[101]P. Mazzucchelli, D. Molteni, N. Di Buono, E. Cottino, "3D GPR realtime automated detection of buried utilities," in Proc. Symp. Applic. Geophyis. Engin. Environm. Probl., SAGEEP, 2012.

[102]L. Crocco, G. Prisco, F. Soldovieri, N.J. Cassidy, "Early-stage leaking pipes GPR monitoring via microwave tomographic inversion," J. Appl. Geophys., vol. 67, no. 4, pp. 270-277, 2009.

[103]A. Rovida, R. Camassi, P. Gasperini, M. Stucchi, CPTI11, la versione 2011 del Catalogo Parametrico dei Terremoti Italiani. Milano, 2011.

[104]L. Orlando, "Semiquantitative evaluation of massive rocks quality using ground penetrating radar," J. Appl. Geophys., vol. 52, no. 1, 2013.

[105]L. Longoni, D. Arosio, M. Scaioni, M. Papini, L. Zanzi, R. Roncella, D. Brambilla, "Surface and subsurface non-invasive investigations to improve the characterization of a fractured rock mass," J. Geophys. Engin., vol. 9, no. 5, 2012.

[106]C. Pauselli, C. Federico, A. Frigeri, R. Orosei, M. R. Barchi, G. Basile, "Ground penetrating radar investigations to study active faults in the Norcia Basin (central Italy)," J. Appl. Geophys., vol. 72, 2010.

[107]M. Ercoli, C. Pauselli, A. Frigeri, E. Forte, C. Federico, "Geophysical paleoseismology" through high resolution GPR data: A case of shallow faulting imaging in Central Italy, J. Appl. Geophys., vol. 90, 2013.

[108]S. Salvi, F. R. Cinti, L. Colini, G. D’Addenzio, F. Doumaz, E. Pettinelli, "Investigation of the active Celano-L'Aquila fault system, Abruzzi (central Apennines, Italy) with combined ground-penetrating radar and palaeoseismic trenching," Geophys. J. Int., vol. 155, no. 3, 2003.

[109] ISTAT. $6^{\circ}$ Censimento generale dell'agricoltura, 2010.

[110]A. Di Matteo, E. Pettinelli, E. Slob, "Early-time GPR signal attributes to estimate soil dielectric permittivity: a theoretical study," IEEE Trans. on Geos. Rem. Sens., vol. 51, no. 3, pp. 1643-1654, 2013.

[111]E. Chianese, M. D’Emilio, M. Bavusi, V. Lapenna, M. Macchiato, "Magnetic and ground probing radar measurements for soil pollution mapping in the industrial area of Val Basento (Basilicata Region, Southern Italy): a case study," Environm. Geol., vol. 49, no. 3, 2006.

[112]L. B. Conyers, Ground-penetrating Radar for Archaeology. Walnut Creek, CA., United States: AltaMira Press Ltd., 2004

[113]D. Goodman, "Ground-penetrating radar simulation in engineering and archaeology," Geophys., vol. 59, pp. 224-232, 1994.

[114]Ministero per i Beni Culturali, Minicifre della Cultura, 2011.

[115] V. Basile, M. T. Carrozzo, S. Negri, L. Nuzzo, T. Quarta, A. V. Villani, "A ground-penetrating radar survey for archaeological investigations in an urban area (Lecce, Italy)," J. Appl. Geophys., vol. 44, no. 1, 2000.

[116] S. Negri, G. Leucci, "Geophysical investigation of the Temple of Apollo (Hierapolis, Turkey)," J. Archaeol. Sci., vol. 33, no. 11, 2006.

[117]L. Nuzzo, G. Leucci, S. Negri, "GPR, ERT and magnetic investigations inside the Martyrium of St Philip, Hierapolis, Turkey," Archaeol. Prosp., vol. 16, no. 3, pp. 177-192, 2009. 
[118]L. Sambuelli, L.V. Socco, L. Brecciaroli, “Acquisition and processing of electric, magnetic and GPR data on a Roman site (Victimulae, Salussola, Biella)," J. Appl. Geophys., vol. 41, no. 2-3, pp. 189-204, 1999.

[119]L. Orlando, F. Soldovieri, "Two different approaches for georadar data processing: a case study in archaeological prospecting," Journal of Applied Geophysics vol. 64 issue 1-2, p. 1-13, 2008.

[120]R. G. Francese, E. Finzi, G. Morelli, "3-D high-resolution multi-channel radar investigation of a Roman village in Northern Italy", J. Appl. Geophys., vol. 67, no. 1, pp. 44-51, 2009.

[121]R. Serandrei-Barbero, G. Zanon, "The Italian Alps," in: Satellite Image Atlas of Glaciers of the World- Europe (1993), USGS,1993.

[122]A. Godio, "Georadar measurements for snow cover density," Amer. J. Appl. Sci., vol. 6, pp. 414-423, 2009.

[123]M. Previati, A. Godio, S. Ferraris, "Validation of spatial variability of snowpack thickness and density obtained with GPR and TDR methods," J. Appl. Geophys., vol. 75, pp. 284-293, 2011.

[124]E. Forte, M. Dossi, R. R. Colucci, M. Pipan, "A new fast methodology to estimate the density of frozen materials by means of common offset GPR data," J. Appl. Geophys., vol. 99, pp. 135-145, 2013.

[125] United Nations, Convention on the Prohibition of the Use, Stockpiling, Production and Transfer of Anti-Personnel Mines and on their Destruction, 18 September 1997.

[126]L. Zanzi, M. Lualdi, H. M. Braun, W. Borisch, G. Triltzsch, "An ultra high frequency radar sensor for humanitarian demining tested on different scenarios in 3D imaging mode," Proceedings of SPIE, 2002.

[127]G. Alli, C. Bonopera, A. Sarri, G. Pinelli, G. De Pasquale, "Data processing for mine-detection polarimetric Ground Penetrating Radar array," in Proc. 10th Int. Conf. Ground Penetrat. Radar; Delft, NL, 2004.

[128] M. Balsi, S. Esposito, F. Frezza, P. Nocito, P. M. Barone, S. E. Lauro, E. Mattei, E. Pettinelli, G. Schettini, C. Twizere, "GPR measurements and FDTD simulations for landmine detection," in Proc. 13th Int. Conf. Ground Penetrat. Radar (GPR 2010); Lecce, Italy, 2010.

[129]A. Giannopoulos, GprMax, a Ground Penetrating Radar simulation tool, ver. 2.0, 2005, http://www.gprmax.org.

[130]L. Nuzzo, G. Alli, R. Guidi, N. Cortesi, A. Sarri, G. Manacorda, "A new densely-sampled Ground Penetrating Radar array for landmine detection," in Proc. 15th Int. Conf. Ground Penetrat. Radar, 2014.

[131]D. J. Daniels, Surface-penetrating Radar, The Institution of Electrical Engineers, London, 1996.

[132] Italian National Institute for Environmental Protection and Research (INSPRA), Landslides in Italy, Special Report 2008, 2008.

[133]L. Crocco, V. Ferrara, "A review on ground penetrating radar technology for the detection of buried or trapped victims," in Proc. Int. Conf. Collabor. Technol. Syst. (CTS), Minneapolis, 2014.

[134]F. Soldovieri, R. Solimene, G. Prisco, "A multiarray tomographic approach for through-wall imaging," IEEE Trans. on Geos. Rem. Sens., vol. 46, no. 4, pp. 1192-1199, 2008.

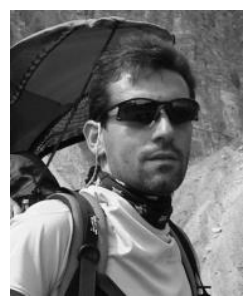

A. Benedetto is Full Professor of roads, railways and airports at the Department of Engineering of Roma Tre University. His research interests include the applications of GPR and other NDTs to civil engineering. $\mathrm{He}$ is Editor in Chief of Advances in Transportation Studies, Associate Editor of Geoscientific Instrumentation, Methods and Data Systems (GI - EGU) and served as Guest Editor for many international journals. He is also member of the editorial boards and referee for other prominent international journals. He is the General Chairman of the Road Safety and Simulation Permanent Steering Committee and organizer of the first and forth international Conferences RSS2007 and RSS2013. He is Convener and coConvener at the EGU GA for the Session GI3.1 "Civil Engineering Applications of GPR" since 2011. He played the role of Chairman and member of the Scientific Committee at the International GPR and IWAGPR conferences. Since 2013 he is the Editorial Coordinator of the COST Action TU1208.

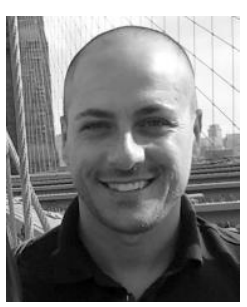

F. Tosti received the MSc and Engineering degree cum laude in road transportation and infrastructures from the Department of Engineering of Roma Tre University in 2010. In 2014, he has obtained his Ph.D. with European Doctorate Label (excellent rating) in civil engineering from the same department, wherein he subsequently held a post-doc position. Since 2016 he is Lecturer (Research Fellow) in "Applications of GPR" at the School of Computing and Engineering of the University of West London. His research interests include the development of GPR- and complementary NDT-based methods in civil engineering. He is the leader of Project 2.5 within the EU funded COST Action TU1208. Since 2013 he is co-Convener at the EGU GA for the Session GI3.1 "Civil Engineering Applications of GPR". He has served as ECSs" EGU Representative of the "Geosciences Instrumentation \& Data Systems" Division for the year 20152016. He was Chairman in International conferences and meetings on GPR and road safety issues, and served as Guest Editor in various International journals.

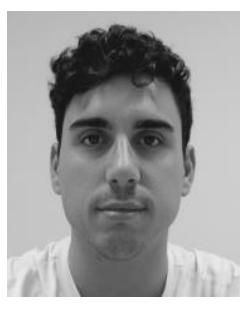

L. Bianchini Ciampoli received the MSc and Engineering degree in road transportation and infrastructures from the Department of Engineering of Roma Tre University in 2014. Since 2015 he is pursuing the Ph.D. degree at the same department, focusing his research work on the evaluation of the mechanical behavior of road and railway structures and materials using NDT methods. In 2014 and 2015 he was hosted as visiting researcher at the Delft University of Technology (TU Delft, $\mathrm{NL}$ ) and the University of West London (UWL, UK). He is currently a member of the EU funded COST Action TU1208. $\mathrm{He}$ has authored and co-authored several publications in International journals and conference proceedings. $\mathrm{He}$ is a reviewer in several International journals.

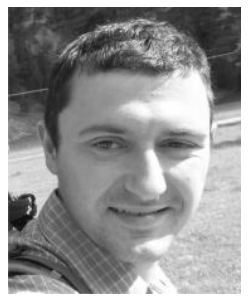

F. D'Amico was born in Rome, Italy, in 1979. In 2004, he graduated in civil engineering at Roma Tre University. In 2009, he received his Ph.D. in sciences of civil engineering from the same University. His research work is focused on road infrastructures design, road safety issues and road pavement maintenance systems. Since 2005 he has developed several studies on the application of GPR in non-destructive analyses of road damages and faults. His current research interests are focused on both implementing GPR-based innovative methods for more effective pavement management inspections and on the evaluation of the driver's behavior in virtual reality by interactive driving simulator. He has served as reviewer and guest editor for several international journals. $\mathrm{He}$ is a technician and professor of "road design" at the Engineering Department of Roma Tre University (2009-present). He was a member of the organizing committee of the Road Safety and Simulation Conference in 2007 and 2013. 